\title{
UMA (RE) LEITURA DE KAFKA, ATURDIMENTO E LINGUAGEM N'O PROCESSO
}

Renato Selayaram ${ }^{1}$

\begin{abstract}
RESUMO: O presente artigo busca fazer uma análise do livro O Processo, de Franz Kafka, apresentando o autor e contextualizando a obra, buscando proporcionar ao leitor a compreensão do assombro provocado pelas idéias expostas pelo escritor tcheco, para que, ao final, não nos entreguemos ao desalento.

Palavras chave: Direito; Estado; Tirania; Justiça.

ABSTRACT: This article seeks to analyze the book The Trial by Franz Kafka, the author presenting and contextualizing the work, seeking to provide the reader an understanding of the ideas expressed astonishment caused by the Czech writer, so in the end not to give ourselves discouragement.
\end{abstract}

Keywords: Law, State, Tyranny, Justice.

\section{Introdução}

Franz Kafka não é para ser apenas lido, mas apreciado avidamente, relido. Não resulta fácil encontrar, na história universal da literatura, um escritor que mostre uma interioridade como a que manifestou Franz Kafka em sua obra. É certo que muitos escritores utilizaram a criação literária como veículo terapêutico para atenuar obsessões internas e outras angústias, mas poucos, muito poucos, conseguiram moldar em preto e branco a eterna preocupação existencial de uma forma tão sublime como o escritor tcheco.

É possível sentir-se, na obra de Kafka, a tormenta e a angústia. Poucos como ele expressaram a incongruência da vida diária. Atraído pela filosofia e pelo onírico - aquilo que resulta dos sonhos, escreveu sobre o desânimo do homem frente ao absurdo do mundo.

Ler Kafka é submeter-se a uma das experiências mais extraordinárias, por sua intensidade e complexidade, que nos proporciona a literatura moderna. Não porque se trate de um autor que proponha envolver a realidade em mistério, ocultando-a, mas porque penetra nela de forma tão profunda, de maneira que existem, conforme Georg Luckáks², poucos

\footnotetext{
1 SElAYARAM, Renato. Mestre em Direito, Especialista em Ciências Políticas, Professor de Direito Internacional.

${ }^{2}$ Filósofo húngaro (1885-1971).
} 
escritores que conseguiram dar forma à originalidade e simplicidade da concepção e representação do mundo.

\section{O autor}

A sinceridade é de todas as qualidades Kafkianas a que, paradoxalmente, se relaciona mais estreitamente com a dificuldade que deve vencer o leitor para se familiarizar com o caráter difícil, anormal, do genial escritor.

Kafka nasceu em Praga, capital da República Tcheca, no seio de uma família de comerciantes, integrantes de uma dupla minoria na cidade onde nasceu, de língua alemã e judia. Teve três irmãos, com os quais viveu a maior parte de sua vida. Muito embora tenha estado comprometido por duas vezes, nunca se casou.

Aos vinte e três anos de idade se graduou em Direito, começando a trabalhar como empregado em companhias de seguro, atividade que alternou com a leitura daqueles que foram suas grandes influências literárias: Ibsen, Spinoza, Nietzsche, Kierkegaard, Flaubert, Hebbel e Stiffer.

Os temas da obra de Kafka são a solidão, a frustração e o angustiante sentimento de desespero que experimenta o indivíduo ao se ver ameaçado por forças desconhecidas, as quais não consegue compreender e que se acham fora de seu controle.

O estilo lúcido e irônico de Kafka, que mezcla fantasia e realidade, dá a sua obra um ar claustrofóbico e assustador, como em uma de suas obras mais famosas, "Metamorfose" (1915).

Durante sua curta vida, Kafka foi pouco conhecido como escritor, pois a maior parte da sua obra literária foi publicada após sua morte, graças ao escritor checoslovaco Max Brod, seu amigo pessoal e biógrafo.

\section{A obra}

Passo, agora, à análise da obra "O Processo", a qual, resumidamente, é a seguinte: Josef $\mathrm{K}$, bancário, ao despertar certa manhã na pensão onde mora, é preso por uns homens vestidos de preto, os quais, sem maiores delongas, o interrogam no quarto ao lado. Toda a narrativa segue sem que se conheça quem teria denunciado Josef $\mathrm{K}$. às autoridades e o motivo de estar sendo preso. Apesar disso, o personagem central luta o tempo todo para 
descobrir do que estava sendo acusado, quem o acusava e com embasamento em que lei. No final, Josef K. já se achava sem ânimo para prosseguir lutando contra um processo do qual ele nada conhecia, estando apático e indiferente. Após escutar na Catedral a "parábola sobre a lei”, que lhe é narrada por um Capelão e com ele discutir o seu sentido, no capítulo final vemos que outros homens o levam preso e acabam por matá-lo.

Para a interpretação deste trabalho, a partir da perspectiva escolhida, a do Direito, convém partir de um dado: em uma análise literária da obra de Kafka é possível destacar que tanto o protagonista de "O Processo"3 quanto o de "A Metamorfose"4, no início da história abrem os olhos na cama e, após os acontecimentos que se seguem, não tem consciência de saber se realmente estão acordados.

Pois tais acontecimentos são um pesadelo que continua na realidade. Assim, a chave para a construção literária de Kafka não é a evocação de um passado que afeta a nossa realidade presente, é uma realidade que segue a lógica dos sonhos. O que determina que o relato seja o desenvolvimento de um absurdo, de acordo com sua própria lógica interna, daquele evento inicial.

Esta chave também está presente em outras obras de Kafka. Entretanto, diferentemente das demais, cabe observar que no começo de "O Processo" não nos encontramos diante de um fato, por assim dizer, da natureza, como foi a transformação em besouro do protagonista de "A Metamorfose", senão ante comportamentos humanos, pois o que nos conta Josef K. é que foi detido em sua casa e que isto ocorreu, provavelmente, por denúncia de algum desconhecido.

O relato se situa, desde o início, no mundo do Direito. Mas interessante notar que, além disso, desde o início, também estabelece um claro contraste com outro mundo jurídico, aquele em que viveu o protagonista antes do pesadelo. Pois diante da presença de "homens de negro" na Pensão e seu comportamento irregular, Josef K. duvida se eles pertencem a qualquer departamento do governo. Somando-se à história, então, um fato significativo, a saber, que K. foi um membro de um Estado constitucional, onde havia paz e ordem e as leis eram cumpridas.

Pois bem, o mundo do direito em que se verá imerso Josef K. desde que acorda e é preso é tecido por muitos detalhes, o que torna muito difícil para refletir fielmente aqui.

\footnotetext{
${ }^{3}$ Processo, O. Franz Kafka. Porto Alegre: L\&PM, 2006.

${ }^{4}$ Metamorfose, A. Franz Kafka. São Paulo: Cia. das Letras, 1997.
} 
Entretanto, ele possui certas características centrais, as quais indico brevemente as três que, a meu ver, são as mais relevantes.

A primeira é que, ao contrário do Estado de Direito em que antes vivia Josef K., agora há apenas um poder, o dos juízes, uma vez que ao longo da história, não há referência aos outros poderes do Estado e só fala, com efeito, em funcionários da justiça. Uma categoria muito ampla que varia de juízes até o Capelão da prisão e os homens de preto. E sobre esse único poder, o judiciário, onde tramitam os personagens restantes, sejam eles advogados que buscam a amizade dos juízes ou dos réus, de quem se espera um bom comportamento, que agrade aqueles em todos os momentos; atitude esta que os primeiros projetam sobre os acusados, como se pode observar no tratamento que recebe o acusado Block na casa do Advogado Huld.

A segunda é o processo criminal em si, que ao longo da história vai tomando forma, com verdadeiro rigor, como a antítese de um julgamento com todas as garantias para o réu. Este não sabe do que é acusado e, embora se acredite inocente, na verdade não sabe como demonstrar. O que leva Josef K., ao representar a si mesmo depois de dispensar o advogado, pensar que deve redigir um documento em que conte cuidadosamente todos os fatos de sua vida e tentar explicá-los, dando-lhes uma direção favorável, uma tarefa que, em seguida, reconhece impossível. Tampouco tem direito à defesa e apoio jurídico, pois nos é dito que os advogados são na verdade apenas tolerados, mas não reconhecidos pelos juízes e, em alguns procedimentos, são totalmente excluídos. De modo que sua razões escritas frente acusações que não conhece, são eruditas, mas vazias de conteúdo e que, de ordinário, não apenas não são lidas, mas lhe são devolvidas. E contra a presunção de inocência do acusado, no mundo em que vive Josef K. se parte de uma presunção de culpa do acusado; presunção contra as quais nada valem as provas em contrário. Pois como lhe dirá Titorelli, frente à justiça nenhuma prova é válida, vez que, já que foi dada forma à acusação, está firmemente convencida da culpa do réu. O que determina, na lógica interna do pesadelo, que não pode ser produzida uma absolvição real, mas apenas uma absolvição aparente", que embora contenha uma declaração de inocência, o processo pode ser reaberto a qualquer momento ou um adiamento ilimitado que estende indefinidamente o processo.

Finalmente, também parece relevante considerar tanto a hierarquia interna quanto o comportamento dos Juízes. Os de primeiro grau, nos tribunais inferiores, apenas recebem declarações e escrevem relatórios para os Juízes do Tribunal Superior, que são os que podem decidir o adiamento ilimitado ou absolvição aparente, porque o direito de ser completamente 
livre pertence somente ao Supremo Tribunal, muito embora isto seja uma possibilidade quase impossível, segundo Titorelli, pois ninguém pode chegar a este tribunal e, por isso, acrescenta ignorar completamente o que pode acontecer lá e que tampouco tem interesse em saber. E quanto ao comportamento, note-se que não é dito, em nenhum momento, que os juízes estão sujeitos à lei, qualquer lei. Ao que se acrescenta que as sentenças proferidas pela justiça são são publicadas e que nem mesmo os Juízes têm o direito de vê-las, de modo que apenas lendas sobreviveram da justiça de tempos passados, mas nem mesmo isto pode ser invocado perante os tribunais.

\section{Uma (re) leitura d'O Processo, aturdimento e linguagem}

Este é, em termos gerais, o mundo jurídico em que vive Josef K. desde o início da história. E se admitirmos, como disse antes, que está construído sobre a lógica interna de sonhos, é razoável considerar que essa lógica não é outra senão a de um mundo onde o Estado e o direito que lhe serve de fundamento, em particular os direitos e liberdades inerentes à pessoa humana, já não existem e, portanto, é um mundo onde apenas reina a arbitrariedade do poder, pois como bem salientou o Min. Marco Aurélio, "reafirme-se a crença no Direito; reafirme-se o entendimento de que, sendo uma ciência, o meio justifica o fim, mas não este àquele, advindo a almejada segurança jurídica da observância do ordenamento normativo. O combate ao crime não pode ocorrer com atropelo da ordem jurídica nacional, sob pena de vir a grassar regime totalitário, com prejuízo para toda a sociedade ${ }^{5}$. Pois Josef $\mathrm{K}$, com efeito, se perguntará indignado em seu depoimento ao Juiz de Instrução o que está escondido por trás do aparato da justiça, alegando que apenas se enfrenta uma poderosa organização, cuja única finalidade é a de prender inocentes e iniciar processos sem sentido, um sistema que, em realidade, pode prescindir de juízes e contentar-se apenas com os verdugos.

Talvez esta última frase tenha levado alguns autores a pensar que $O$ Processo é uma grande sátira sobre os Juízes e Justiça. Mas acredito que essa interpretação não só é muito simples, mas envolve uma nítida subestimação de sua obra. Na verdade, parece que Franz Kafka queria sublinhar este pesadelo, em contraste com o mundo jurídico em que vivia Josef K. São precisamente aqueles a quem é confiada a Justiça, nos termos da lei, os Juízes, os que a abandonam completamente. E, portanto, que apenas exercem um poder arbitrário, pelo qual

\footnotetext{
${ }^{5} \mathrm{STF}-2^{\mathrm{a}} \mathrm{T}-\mathrm{HC}^{\circ}{ }^{\circ}$ 74639-0/RJ/ rel. Min. Marco Aurélio, Diário da Justiça, 31/10/1996.
} 
determinam quem são os réus, sem que exista acusação formal, estabelecem sua culpa sem que possam se defender e, finalmente, ordenam sua execução sem lhes comunicar a sentença. De modo que não é só para realçar a arbitrariedade possível que resulta da existência de um único poder no Estado, como foi feito na concepção de um Estado democrático de Locke ou Montesquieu, mas o fato de que essa arbitrariedade é, paradoxalmente, o trabalho dos Juízes.

Portanto, a medida que Josef K. começa a conhecer o comportamento dos Juízes, por meio de suas conversas primeiramente com o advogado Huld, e com Titorelli mais tarde, e também com outros réus, cresce o horror que o envolve. A este é adicionado, diante de sua tentativa de saber quais são as leis que regem o mundo em que agora vive, o Capelão da prisão, ao lhe narrar a Parábola da Lei, em que conta o caso de um homem que viveu enganado pela lei, para que assim desista de toda possibilidade de conhecê-la. De modo que, progressivamente, vai compreendendo que o pesdelo que está vivendo só pode terminar com sua morte. E, de fato, quando chega esse momento, depois de resistir debilmente, aceita-a, depois de imaginar inutilmente que o homem que faz gestos da janela e contempla sua execução pudesse ser capaz de intervir, mas sem estar certo se ele realmente é a seu favor ou contra.

Se essa interpretação estiver correta, não há dúvida de que $O$ Processo não é apenas uma grande obra literária, mas também uma grande obra sobre o Direito. Como em um negativo, nos mostra, de fato, a segurança em que vive um cidadão em um Estado de Direito, onde os Juízes aplicam a lei e estas são justas porque garantem os direitos e liberdades fundamentais para todos. E, por outro lado, o horror a que o homem pode chegar quando, não estando protegido pelo Direito, senão por uma simples aparência, resta sem defesa alguma ante um poder arbitrário, que pode ser até mesmo, o que é mais terrível, o dos Juízes. Este abandono por parte da justiça faz com que seja não apenas vergonhoso, mas perigoso, considerado da perspectiva do povo e da vítima, como se o poder soberano não visse nessa emulação de atrocidades um desafio que ele mesmo lança e que poderá ser aceito um dia ${ }^{6}$.

Isto pode explicar porque, muitos anos depois de ser escrito, O Processo se converteu não apenas em um clássico moderno, mas uma obra esclarecedora. A esse respeito talvez se pudesse pensar que o êxito desta obra, ocorrido apenas a partir da segunda edição das obras completas de Franz Kafka, em 1952, se deve a que nos mostra o homem ante a angústia de sua vida real, a qual não entende; uma atitude que estava muito próximo ao existencialismo então em vigor. Mas há uma outra explicação, para mim mais convincente: a de que na data

\footnotetext{
${ }^{6}$ FOUCAULT, Michel.
} 
referida, o mundo já havia testemunhado os horrores do nazismo, que havia arrastado as três irmãs mais novas de Franz Kafka para os campos de extermínio, as quais pereceram em circunstâncias ainda mais cruéis do que as do protagonista de O Processo.

Tais horrores pensávamos houvessem desaparecido para sempre. Mas, infelizmente, voltaram a se repetir mais tarde, não só na Europa, no esfacelamento da antiga Iugoslávia, mas também em outros continentes, por diferentes motivos, mas cujo terreno comum é a intolerância por outros seres humanos que sejam diferentes de nós, conforme Barco. ${ }^{7}$ E essa triste constatação faz ainda mais valioso o legado de O Processo para o Direito.

Esta obra, de fato, não nos diz como ocorre a transição de um Estado de Direito para um poder arbitrário, mas mostra claramente que essa mudança pode ocorrer em um momento inesperado, da noite para o dia, como aconteceu com Josef K. O que faz supor, acredito, que em uma sociedade democrática são necessárias tanto uma atitude vigilante como uma luta permanente para que os direitos e liberdades fundamentais do indivíduo sejam respeitados, muito embora seja uma luta que se realize com palavras, para denunciar sua violação. E também, para que possamos conservar tais direitos e liberdades sem que desapareçam de forma inesperada, não basta apenas uma ação individual, isolada, já que o esforço necessário, para ser eficaz, requer a ação conjunta de muitos $^{8}$, opondo-se decididamente desde a sua criação até a materialização dos atos de um poder que não respeita a dignidade humana ${ }^{9}$.

A referência vale para qualquer poder e em qualquer circunstância, mesmo para um Estado onde começaram as declarações dos direitos e liberdades fundamentais dos cidadãos, mas que, surpreendentemente, ao tentar punir os autores de um crime hediondo, distingue entre nacionais e estrangeiros e, a respeito destes últimos, escolhe a via de transferi-los para uma terra distante de seus países de origem e de mantê-los presos e acorrentados em simbólicas gaiolas de metal sob o sol tropical para interrogatório sem a presença de advogados e para oferecer, como o fim de sua situação atual, apenas um processo incerto, uma vez que não sabemos ainda qual vai ser o estatuto dessas pessoas, que garantias legais terão quando vierem a ser julgados ou quando ocorrerá tal julgamento. Este comportamento representa a personificação da expressão latina homo homini lupus, que significa que o homem é o lobo do homem, popularizada por Thomas Hobbes, filósofo inglês do século XVII, utilizada em sua obra Leviatan. A contraposição desta frase é representada pela locução

\footnotetext{
${ }^{7}$ BARCO, Gustavo Emílio Cote.

${ }^{8}$ SELAYARAM, Renato.

${ }^{9}$ ARÉCHAGA, Eduardo Jiménez de e FERRAND, Martin Risso.
} 
homo homini sacra res, atribuída a Sêneca, para quem o homem é algo sagrado para o homem. E assim deveria ser.

\section{Conclusões}

Nos acostumamos a qualificar como Kafkianas certas situações inexplicáveis, que nos surpreendem sobremaneira e que parecem ser produto mais da fantasia do que da realidade. Não é possível que o jovem Kafka, em seu leito de morte, pedindo a seu amigo Max Brod que queimasse tudo o que havia escrito, imaginasse que suas obras passariam a ser um verdadeiro mito para a literatura universal.

Um sistema judicial ineficaz, que apenas reclama recursos, mas não assume de forma séria e efetiva compromissos e responsabilidades para com os cidadãos, torna-se um câncer que dificulta, se não impedir, o progresso de uma sociedade, um Leviatan que mais priva de direitos do que protege o indivíduo. Contra estas maquinações devoradoras e destrutivas está dirigida a crítica de toda obra literária de Kafka. E ainda que admitamos que a situação nos países mais avançados no final do século XX, início do XXI, não é tão atroz como a que ele conta, estará errado quem pense que essas aberrações são fruto passado. Ainda existem, e ressurgirão sempre que negligenciemos. Porque não procedem apenas da maldade, mas da indiferença, que é a fonte mais freqüente de despotismo, da arbitrariedade.

Muito embora a denúncia sobre as injustiças sociais não esteja ausente n'O Processo, não podemos afirmar que se trate de uma obra que trate o Direito como instrumento de opressão. Trata-se, de qualquer modo, da denúncia da justiça como um pesadelo burocrático.

No livro, Kafka não só denuncia instituições que operam em torno de uma burocracia prejudicial, mas também zomba do Estado, de suas contradições e da pouca confiabilidade que possui, apesar de ter o respeito da sociedade. Kafka, vale ressaltar, na maioria de suas obras expressa uma resistência às instituições e ao modo como tais organizações estão estruturadas.

Algumas das maneiras pelas quais o Estado é ridicularizado por Kafka neste trabalho é ter o domingo como um dia designado para conduzir os interrogatórios.

Esta obra mostra a impotência que muitos seres humanos ainda hoje sentem frente às questões monitorados pela burocracia. 
Ele era um visionário, sábio demais para viver, fraco demais para querer lutar, mas a sua fraqueza era a dos homens nobres e justos, que são incapazes de combater o medo, a incompreensão, a falta de amor e a hipocrisia, e que conscientes de sua deficiência, preferem render-se ao vencedor. Seu conhecimento do mundo era extraordinário e profundo. Ele próprio era um mundo extraordinário e profundo.

Suas obras são caracterizadas pela expressão de um surdo temor pelos segredos desconhecidos e a evidente ausência de culpa entre os homens. Ele era um artista de consciência tão escrupulosa que soube permanecer alerta onde os outros, os surdos, se sentiram seguros.

\section{REFERÊNCIAS BIBLIOGRÁFICAS}

ARÉCHAGA, Eduardo Jiménez de, FERRAND, Martin Risso. Introdución al derecho. Edición ampliada y actualizada. Montevideo: Fundación de Cultura Universitária, 2007.

BARCO. Gustavo Emílio Cote. Derecho penal de enemigo en la violência (1948-1966). Bogotá: Editorial Pontifícia Universidad Javeriana, 2010.

FOUCAULT, Michel. Vigiar e punir: nascimento da prisão; trad. de Ligia M. Pondé Vassallo. Petrópolis: Vozes, 1987.

LOCKE, John. Segundo tratado sobre o governo civil: ensaio sobre a origem, os limites e os fins verdadeiros do governo civil. Int. de J.W.Gough; trad. de Magda Lopes e Marisa Lobo da Costa. $3^{\text {a }}$ ed. RJ: Vozes, 1994.

MONTESQUIEU, Charles Louis de Secondat. O espírito das leis. Introdução, tradução e notas de Pedro Vieira Mota. $3^{\text {a }}$ ed. São Paulo: Saraiva, 1994.

MORAES, Alexandre de. Direitos humanos fundamentais: teoria geral, comentários aos arts. $1^{\circ}$ a $5^{\circ}$ da Constituição da República Federativa do Brasil, doutrina e jurisprudência. $7^{\mathrm{a}}$ ed. São Paulo: Atlas, 2006.

SELAYARAM, Renato. Brasil y los derechos humanos. In: CURCI, Juan Ignacio Perez. Los derechos humanos em Latinoamérica. (Coord.). 1ª ed. Buenos Aires: Educa, 2010. 